\title{
IDENTIFIKASI KAWASAN UNTUK PENERAPAN SISTEM RAINWATER HARVESTING (RWH) DI KOTA PALEMBANG DENGAN PENDEKATAN GEOGRAPHIC INFORMATION SYSTEM (GIS)
}

\author{
Imroatul C. Juliana ${ }^{1^{*}}$, Febrinasti Alia ${ }^{2}$, M. Ichwanul Falah ${ }^{3}$, dan Taufik Ari Gunawan ${ }^{4}$ \\ ${ }^{1,2,4)}$ Dosen, Jurusan Teknik Sipil dan Perencanaan - Fakultas Teknik Universitas Sriwijaya, Jl. Raya Palembang-Prabumulih, \\ Km 32 Indralaya, Ogan Ilir, Sumatera Selatan \\ 3) Post graduated, Jurusan Teknik Sipil dan Perencanaan - Fakultas Teknik Universitas Sriwijaya, Jl. Raya Palembang- \\ Prabumulih, Km 32 Indralaya, Ogan Ilir, Sumatera Selatan
}

\begin{abstract}
Rainwater harvesting system (RWH) implementation may be a solution to maximize the water availability and reduce the runoff volume in Palembang City. For successful implementation, it is necessary to identify potential areas for RWH implementation. This study aims to identify areas in Palembang that are potential for implementing the RWH system. An analysis of parameters that affect the classification also conducted. This study used a geographic information system (GIS) approach using rainfall, slope, land use, and soil type parameters which are structured in a hierarchy using the analytical hierarchy process (AHP). Based on the weighted overlay method, it can be concluded that a very potential area for RWH implementation dominated with a wet area, flat slope, dense residential area and the type of soil which is not susceptible to infiltration. Whereas the medium and non-potential areas are dominated by steep and very steep slopes as well as unoccupied land use. Areas of high potential and potential reach $18.17 \%$ and $66.14 \%$ respectively. While the medium and not the potential is $13.66 \%$ and $2.03 \%$. Areas of great potential are in the Buah, Kidul, Sekanak, Sriguna, Bendung, and Selinca Sub Watershed. Non-potential areas are only available in small area in DAS Gandus, Gasing, and Lambidaro Sub Watershed.
\end{abstract}

Key Words: analytical hierarcy process, geoghraphic information system, potential, rainwater harvesting, weighted overlay.

\section{PENDAHULUAN}

Pertumbuhan pendudukan yang semakin pesat merupakan salah satu masalah yang dihadapi oleh kota-kota besar di Indonesia termasuk Kota Palembang. Kta Palembang mengalami kenaikan jumlah penduduk rata- rata sebesar 1,4\% setiap tahunnya (BPS, 2018). Hal ini akan berdampak pada beberapa kondisi dimana salah satunya adalah peningkatan kebutuhan akan air bersih.

Kebutuhan air bersih untuk masyarakat di kota Palembang pada umumnya disediakan oleh PDAM dan dengan memanfaatkan air tanah. Pemakaian air tanah yang terus menerus akan mengakibatkan ketersediaan air tanah semakin sedikit. Dalam siklus hidrologi, kecepatan pengisian air kembali jauh lebih lambat jika dibandingkan dengan kecepatan pengambilannya. Eksploitasi penggunaan air tanah yang berlebihan akan menyebabkan terjadinya land subsidence.

Dampak lain yang ditimbulkan dari peningkatan jumlah penduduk adalah adanya alih fungsi lahan yang secara langsung maupun tidak akan menyebabkan terjadinya banjir. Tingginya limpasan permukaan (runoff) dan tidak maksimalnya fungsi bangunan pengendali banjir menjadi salah satu penyebab terjadinya banjir di Kota Palembang (Al Amin dkk., 2015).

Banjir dan meningkatnya kebutuhan air bersih menjadi permasalahan sumberdaya air yang perlu untuk segera diatasi. Pemanfaatan dan pengelolaan air hujan dengan sistem pemanenan atau rainwater harvesting $(\mathrm{RWH})$ dapat dijadikan salah satu solusi untuk mengurangi volume limpasan dan mengurangi beban pemakaian air tanah atau PDAM.

Kota Palembang yang memiliki curah hujan tahunan antara 2500-2600 mm diperkirakan mampu memenuhi kebutuhan air potable untuk 1 orang dan kebutuhan air non potable sampai dengan 2 orang penghuni (Juliana dkk., 2014).

Penelitian-penelitian sebelumnya menunjukkan bahwa pemanfaatan dan pengelolaan air hujan dengan sistem RWH memberikan keuntungan baik secara ekonomi maupun lingkungan. (Roebuck dkk., 2006; Roebuck dkk., 2010; Zhang dkk., 2009; Tam dkk., 2009; Ryan dkk., 2009; Rahman dkk., 2012; Farreny dkk., 2011; Nagaraj dkk., 2011). Agar keberhasilan penerapan RWH dapat ditingkatkan, maka perlu untuk melakukan identifikasi potensi 
kawasan-kawasan yang ada untuk penerapan sistem RWH. Studi ini bertujuan untuk mengidentifikasi potenai kawasan yang ada di Kota Palembang apakah termasuk yang potensial untuk penerapan sistem RWH serta parameter yang mempengaruhinya. Beberapa parameter seperti hujan, kemiringan lereng, tata guna lahan, dan jenis tanah dapat mempengaruhi keputusan untuk menentukan potensi kawasan tersebut (Mahmoud dkk., 2015).

Identifikasi kawasan yang potensial dapat dilakukan dengan menggunakan pendekatan Geographic Information System (GIS) (Adham dkk., 2018). GIS dipilih dalam studi ini karena dianggap sebagai salah satu teknik yang tepat untuk pengambilan keputusan (Nketiaa dkk., 2013).

\section{METODOLOGI}

Pada penelitian ini dilakukan analisis klasifikasi parameter yaitu hujan, kemiringan lereng, kepekaan tanah terhadap infiltrasi (jenis tanah), dan tata guna lahan. Semua parameter akan diberikan skor (scoring) dengan bobot dan nilai sesuai dengan klasifikasinya masing-masing. Setelah itu, dilanjutkan dengan analisis weighted overlay menggunakan ArcGIS.

Pemberian skor menggunakan metode analytical hierarchy process (AHP) dan disesuaikan dengan tingkat kesesuaiannya. Metode AHP dikembangkan oleh Saaty (1993), dimana metode ini membantu proses pengambilan keputusan yang kompleks dengan menyusun hirarki kriteria dari user dan hasil yang diharapkan dengan beberapa pertimbangan untuk mendapatkan bobot dan prioritas. Metodologi penelitian dapat dilihat pada Gambar 1 .

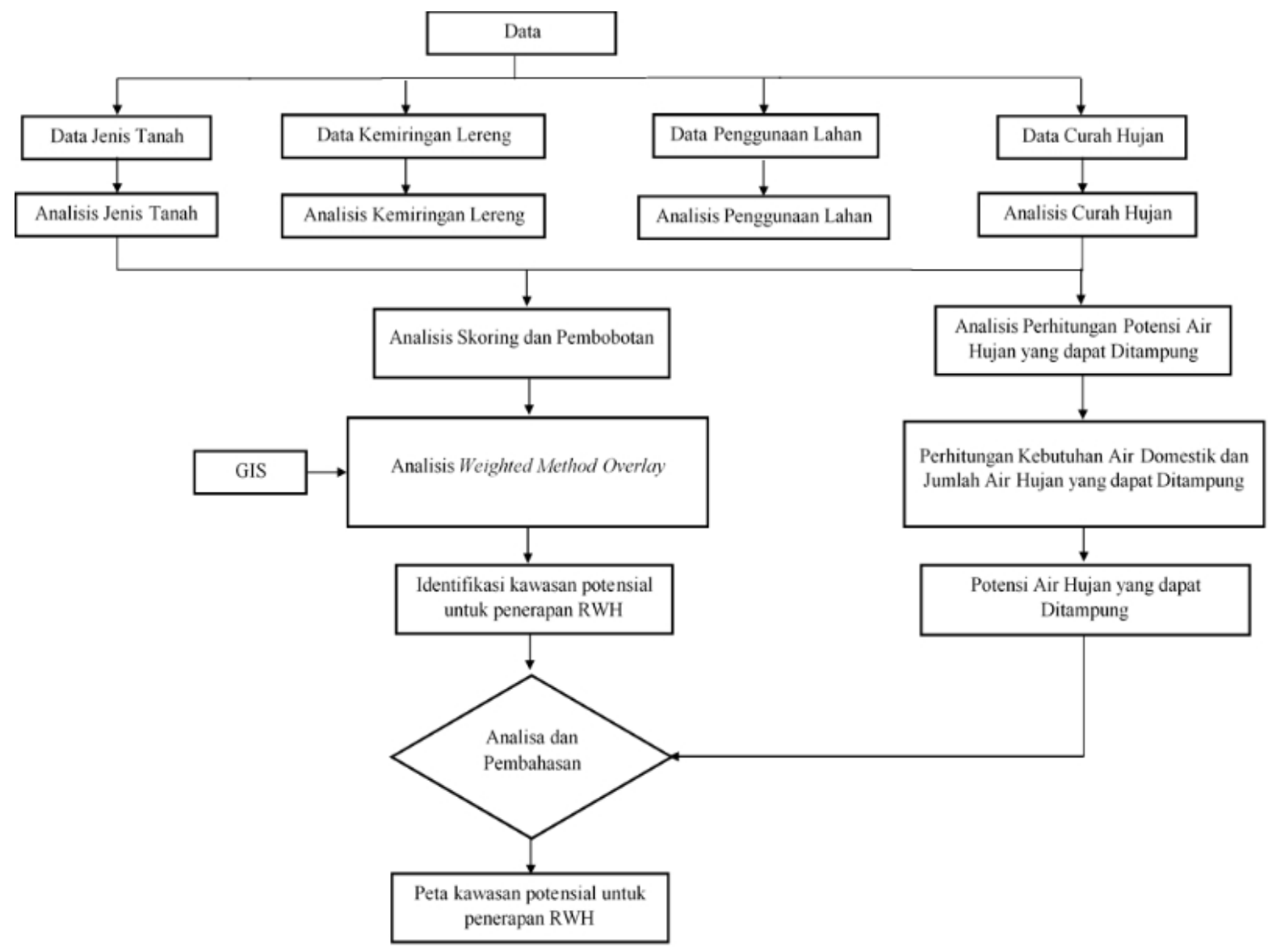

Gambar 1. Metodologi penelitian

Skor dihitung berdasarkan pengaruh masingmasing kelas tehadap potensi untuk penerapan sistem RWH. Skor akan semakin tinggi jika pengaruhnya tinggi, dan semakin rendah jika pengaruhnya kecil (nilai 1 sampai dengan 5).
Masing-masing parameter yang mempengaruhi untuk penerapan sistem RWH akan diberikan pembobotan. Bobot akan semakin tinggi jika pengaruh parameter semakin besar. Pada studi ini, perhitungan pembobotan diadaptasi dari penelitianpenelitian terdahulu dengan melakukan analisis ulang dan uji konsistensi. 


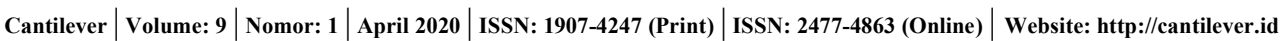

Imroatul C. Juliana, dkk. | Identifikasi Kawasan Potensial untuk Penerapan Sistem RWH di Kota Palembang dengan Pendekatan GIS

Bobot relatif setiap elemen dalam hirarki harus dianalis. Hal ini dilakukan untuk menganalisis tingkat kepentingan pihak-pihak yang berkepentingan terhadap kriteria dan struktur hirarki secara keseluruhan. Penentukan prioritas dari suatu kriteria diawali dengan menyusun perbandingan berpasangan. Perbandingan berpasangan dilakukan dengan membandingkan dalam seluruh kriteria dalam bentuk berpasangan pada setiap sub sistem. Perbandingan tersebut kemudian ditransformasikan dalam bentuk matriks perbandingan berpasangan untuk analisis numerik.

Besarnya potensi volume air hujan yang ditangkap oleh atap suatu bangunan sama dengan volume air hujan yang dapat ditampung dibandingkan dengan jumlah kebutuhan air. Kinerja sistem RWH terutama dipengaruhi oleh curah hujan tahunan, kapasitas tangki penyimpanan, dan luas catchment area (Juliana dkk, 2017).

Selain itu, dihitung juga perkiraan biaya yang harus dikeluarkan untuk instalasi rooftop rainwater harvesting. Harga untuk perhitungan capital cost diambil dari standard harga Kota Palembang Semester I 2018 (Bappeda Litbang Kota Palembang, 2017) dan berdasarkan harga pasar. Perkiraan biaya dihitung untuk beberapa tipe rumah yaitu $36 \mathrm{~m}^{2}, 45 \mathrm{~m}^{2}, 70 \mathrm{~m}^{2}$, dan $100 \mathrm{~m}^{2}$. Ukuran tangki disimulasikan untuk kapasitas 250L, 520L, 1.050L dan 2.000L

\section{HASIL DAN PEMBAHASAN}

\section{Potensi Air Hujan}

Seperti dijelaskan sebelumnya, analisis potensi air hujan dilakukan untuk beberapa ukuran atap. Curah hujan tahunan Kota Palembang dengan rerata sebesar 2621,4 mm/tahun digunakan dalam analisis. Koefisien volume curah hujan yang dapat ditangkap oleh atap (C) diambil 0,8 yang merupakan koefisien atap bangunan. Perhitungan volume air hujan yang dapat ditangkap oleh atap sebagai catctment area per tahun menggunakan Persamaan 1 berikut:

Volume air hujan yang ditangkap = luas catchment area atap x curah hujan tahunan x C

Persentase kinerja sistem RWH untuk masingmasing ukuran atap dijelaskan pada Tabel 1. Dari Tabel 1 dapat dilihat bahwa jumlah volume air hujan ditampung sebanding dengan ukuran atap. Volume air hujan yang ditampung akan semakin banyak jika ukuran atap (catchment area) semakin besar yang mengakibatkan kinerja sistem RWH akan semakin baik.
Tabel 1. Volume air hujan dan persentase kinerja sistem RWH

\begin{tabular}{ccc}
\hline Ukuran atap & Volume air hujan yang ditampung & Kinerja sistem \\
\hline $\mathrm{m}^{2}$ & (liter/tahun) & $(\%)$ \\
36 & $75.497,67$ & 27,22 \\
45 & $94.372,08$ & 34,02 \\
70 & $146.801,02$ & 52,92 \\
100 & $209.715,74$ & 75,60 \\
\hline
\end{tabular}

Estimasi biaya yang dibutuhkan untuk membangun instalasi sistem RWH untuk tipe rumah dengan ukuran terkecil $36 \mathrm{~m}^{2}$ sampai ukuran terbesar $100 \mathrm{~m}^{2}$ dan kapasitas tangki 250L sampai dengan 2000L adalah Rp.4.014.900,- sampai Rp. $6.500 .700,-$.

\section{Pembobotan Hirarki Kriteria}

Pairwise comparison (perbandingan berpasangan) satu kriteria dibandingkan dengan yang lain didefinisikan dengan kawasan yang sangat potensial, kawasan potensial, kawasan potensial sedang, kawasan tidak potensial dan kawasan sangat tidak potensial. Bobot prioritas dari kawasan potensial untuk penerapan sistem RWH didapatkan dari penelitian-penelitian sebelumnya (Mahmoud dkk., 2015; Adham dkk., 2018; Darmawan dkk, 2017) dengan susunan hirarki seperti pada Gambar 2.

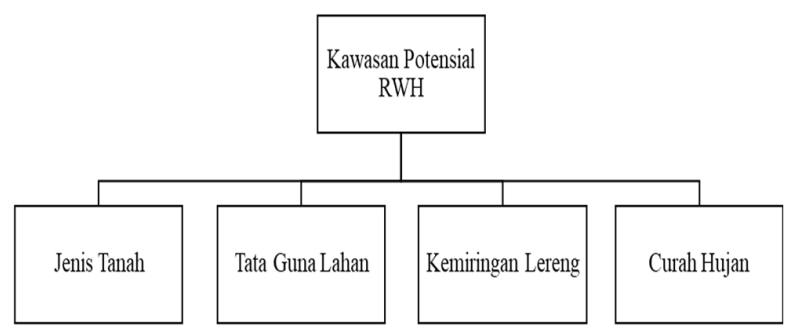

Gambar 2. Susunan hirarki bobot prioritas

Dengan pertimbangan - pertimbangan tersebut disusun matriks perbandingan berpasangan seperti pada Tabel 2.

Tabel 2. Matriks perbandingan

\begin{tabular}{lcccc}
\hline \multicolumn{1}{c}{ Kriteria } & Jenis Tanah & $\begin{array}{c}\text { Tata Guna } \\
\text { Lahan }\end{array}$ & $\begin{array}{c}\text { Kemiringan } \\
\text { Lereng }\end{array}$ & $\begin{array}{c}\text { Curah } \\
\text { Hujan }\end{array}$ \\
\hline Jenis Tanah & 1 & 6 & 5 & 3 \\
Tata Guna Lahan & $1 / 6$ & 1 & $1 / 2$ & $1 / 4$ \\
Kemiringan & $1 / 5$ & 2 & 1 & $1 / 3$ \\
Lereng & $1 / 3$ & 4 & 3 & 1 \\
Curah Hujan & 1,7 & 13 & 9,5 & 4,583 \\
\hline Jumlah & & & &
\end{tabular}

Hasil rerata bobot relatif untuk setiap baris dinyatakan sebagai bobot prioritas. Semua kriteria yang sudah dinormalkan disusun menjadi matriks faktor pembobotan hirarki pada Tabel 3 berikut: 
Tabel 3. Matriks bobot prioritas

\begin{tabular}{lcc}
\hline \multicolumn{1}{c}{ Kriteria } & Bobot Prioritas & $\begin{array}{c}\text { Persentase Bobot Prioritas } \\
(\%)\end{array}$ \\
\hline Jenis Tanah & 0,56 & 56 \\
Tata Guna Lahan & 0,07 & 7,2 \\
Kemiringan Lereng & 0,11 & 11,3 \\
Curah Hujan & 0,26 & 25,8 \\
\hline Jumlah & 1 & 100 \\
\hline
\end{tabular}

CI yang didapat adalah 0,045 dengan syarat konsisten apabila kurang dari 0,100 sehingga matriks penyunan kriteria dianggap konsisten.

\section{Analisis Kemiringan Lereng}

Peta kontur diinterpolasi untuk menghasilkan peta digital elevation model (DEM). DEM disajikan secara digital dalam bentuk ketinggian dari permukaan bumi. Peta DEM ini akan digunakan untuk menghasilkan peta kemiringan lereng dengan koordinat 3D $(\mathrm{x}, \mathrm{y}, \mathrm{z})$. Pemodelan dilakukan dengan membagi area-area yang terhubung. Area tersebut terbentuk dari titik-titik pada peta kontur yang dapat berupa hasil interpolasi atau titik sampel permukaan tanah. Interpolasi menggunakan metode 3D analyst spatial (slope) akan menghasilkan DEM seperti Gambar 3.

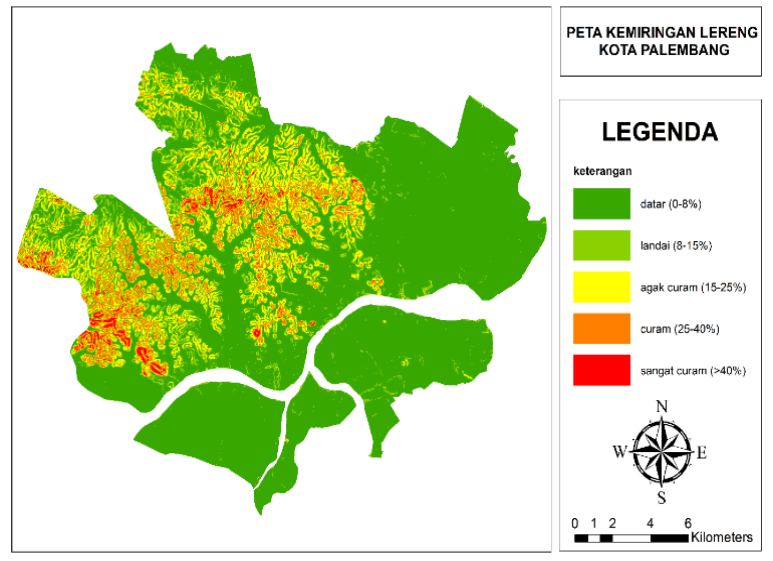

Gambar 3. Peta lereng Kota Palembang

Gambar 3 menunjukkan secara umum Kota Palembang memiliki lereng yang datar atau kawasan dataran rendah dengan persentase 93,13\%. Pembagian kemiringan lereng disajikan pada Tabel 4 berikut:

Tabel 4. Kemiringan lereng Kota Palembang

\begin{tabular}{clcc}
\hline No. & Klasifikasi & Luas ( Ha) & Persentase Luas (\%) \\
\hline 1 & Datar & $3.154,354$ & 93,13 \\
2 & Landai & $1.903,066$ & 5,62 \\
3 & Agak Curam & 391,414 & 1,16 \\
4 & Curam & 31,808 & 0,09 \\
5 & Sangat Curam & 2,642 & 0,01 \\
\hline & Total & $3.3882,285$ & 100,00 \\
\hline
\end{tabular}

\section{Analisis Tata Guna Lahan}

Berdasarkan hasil analisis, pemukiman mendominasi penggunaan lahan di Kota Palembang dengan luasan sebesar 27,98\%.

Gambar 4 dan Tabel 5 berikut menjelaskan pembagian peta dan persentase tata guna lahan Kota Palembang.

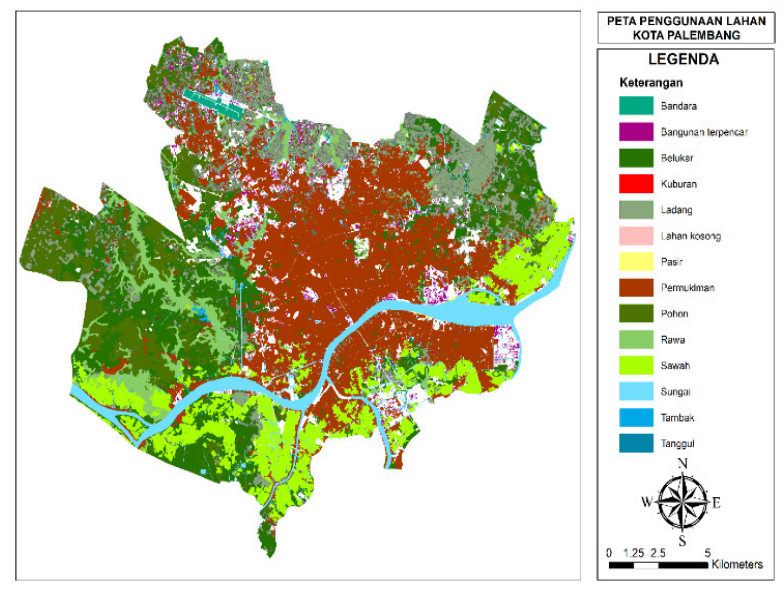

Gambar 4. Peta tata guna lahan Kota Palembang

Tabel 5. Tata guna lahan Kota Palembang

\begin{tabular}{clcc}
\hline \multirow{2}{*}{ No. } & \multirow{2}{*}{ Tata guna lahan } & \multicolumn{2}{c}{ Luas Lahan } \\
\cline { 3 - 4 } & & $(\mathrm{Ha})$ & $\%$ \\
\hline 1 & Airport & 116,681 & 0,4 \\
\hline 2 & Bangunan berpencar & 277,229 & 0,9 \\
\hline 3 & Semak belukar & $5.782,455$ & 18,5 \\
\hline 4 & Pemakaman & 2,937 & 0,01 \\
\hline 5 & Ladang & $4.103,474$ & 13,1 \\
\hline 6 & Tanah kosong & 10,178 & 0,03 \\
\hline 7 & Pasir & 20,693 & 0,07 \\
\hline \multirow{2}{*}{8} & Pemukiman / & $8.736,560$ & 27,9 \\
\hline 9 & perumahan & $4.186,875$ & 13,41 \\
\hline 10 & Pohon & $1.903,928$ & 6,1 \\
\hline 11 & Pawa & $3.807,813$ & 12,2 \\
\hline 12 & Sungawahan & $1.973,046$ & 6,3 \\
\hline 13 & Tambak & 301,092 & 0,9 \\
\hline 14 & Tanggul & 2,017 & 0,01 \\
\hline & Total luas & $31.224,978$ & 100,00 \\
\hline
\end{tabular}

\section{Analisis Jenis Tanah Terhadap Infiltrasi}

Jenis-jenis tanah diklasifikasikan berdasarkan tingkat kepekaan tanah terhadap infiltrasi seperti pada Gambar 5.

Jenis tanah diklasifikasikan menjadi peka, sangat peka, dan tidak peka. Berdasarkan hasil analisis, sebagian besar jenis tanah di Kota Palembang termasuk ke dalam klasifikasi tidak peka dengan luas permukaan $45,7 \%$. Jenis tanah berikutnya diikuti dengan jenis sangat peka $38,3 \%$ dan peka $16,02 \%$. 
Cantilever | Volume: 9 Nomor: 1 | April 2020 ISSN: 1907-4247 (Print) $\mid$ ISSN: 2477-4863 (Online) $\mid$ Website: http://cantilever.id

Imroatul C. Juliana, dkk. | Identifikasi Kawasan Potensial untuk Penerapan Sistem RWH di Kota Palembang dengan Pendekatan GIS
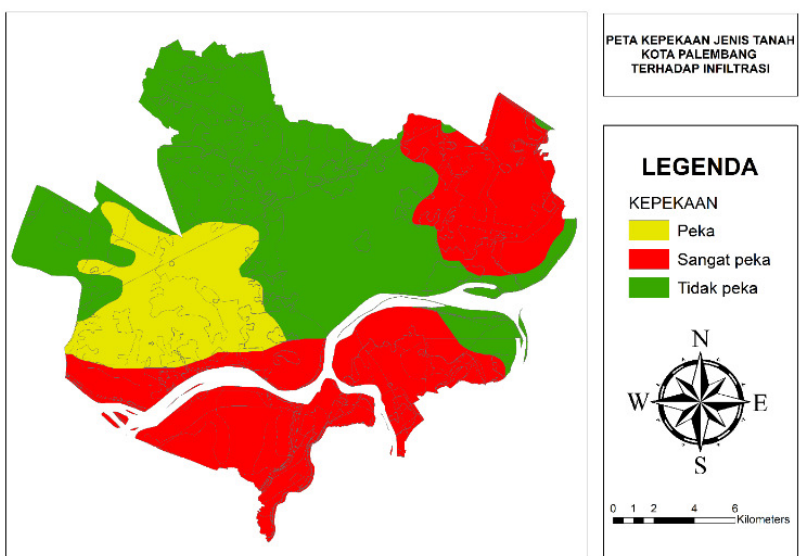

Gambar 5. Peta jenis tanah Kota Palembang

\section{Analisis Curah Hujan}

Rerata curah hujan dihitung dari data lima (5) stasiun hujan yaitu Stasiun Kertapati, Plaju, Klimatogi Palembang, Sultan Mahmud Badarudin II, dan Sekojo. Masing-masing kawasan di Kota Palembang dikelompokkan berdasarkan titik koordinat pada peta. Pengelompokan dengan metode Poligon Thiessen dapat dilihat pada Gambar 6.

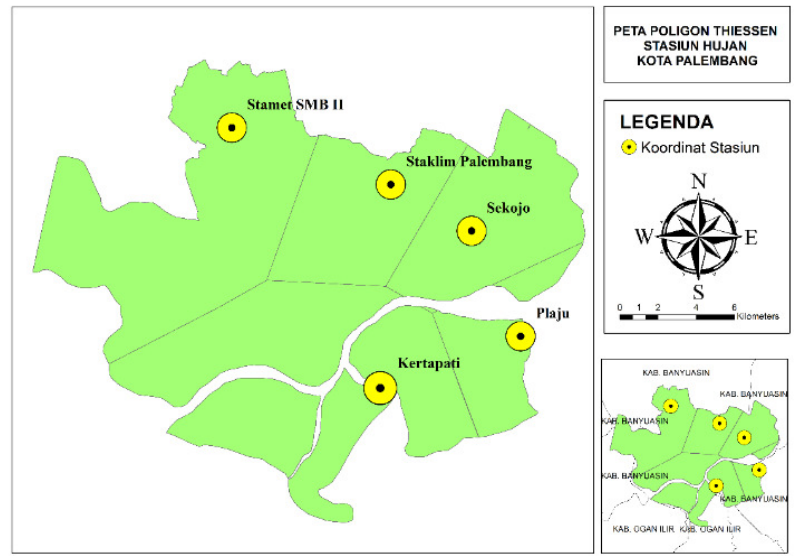

Gambar 6. Peta poligon thiessen stasiun hujan Kota Palembang

Dari pembagian poligon Thiessen didapat lingkup kawasan pada masing masing stasiun hujan seperti pada Gambar 7.

Berdasarkan hasil analisis, Kota Palembang termasuk kawasan yang basah karena memiliki curah hujan tahunan 2500-3000 $\mathrm{mm} / \mathrm{tahun}$. Kawasan dengan curah hujan minimal 2500 $\mathrm{mm} /$ tahun termasuk ke dalam kawasan yang potensial untuk penerapan sistem RWH (Juliana dkk, 2017). Oleh karena itu, dapat disimpulkan bahwa Kota Palembang adalah kawasan yang potensial untuk penerapan sistem RWH.

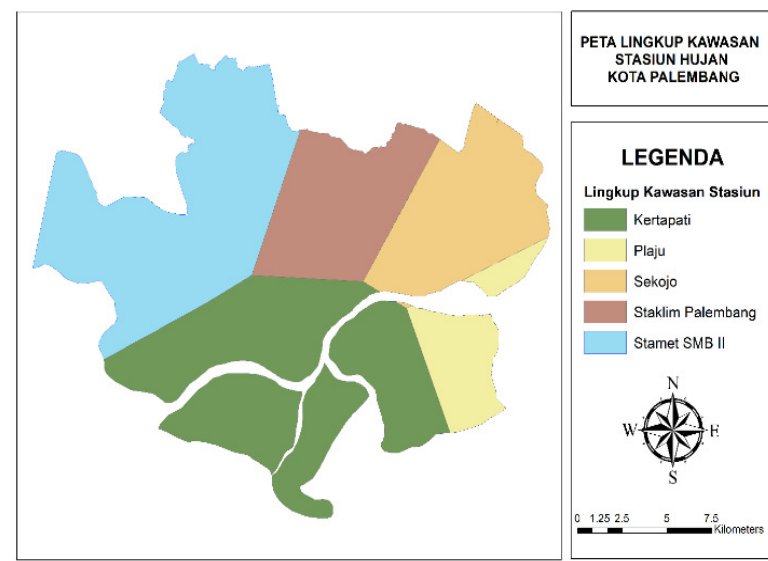

Gambar 7. Peta pengelompokan kawasan stasiun hujan Kota Palembang

\section{Analisis Pembobotan dan Skoring}

Penentuan kawasan untuk penerapan sistem RWH dianalisis berdasarkan tingkatan kelas. Tingkatan kelas ini didapat dari perhitungan bobot dan skoring parameter serta variabel yang mempengaruhi. Harkat penentuan kawasan untuk penerapan sistem RWH dirangkum dalam Tabel 6 berikut:

Tabel 6. Harkat kawasan untuk penerapan sistem RWH

\begin{tabular}{|c|c|c|c|c|}
\hline No. & Parameter & Klasifikasi & Skoring & Bobot \\
\hline \multirow{5}{*}{1} & \multirow{5}{*}{$\begin{array}{l}\text { Kemiringan } \\
\text { Lereng }\end{array}$} & Datar & 5 & \multirow{5}{*}{0,562} \\
\hline & & Landai & 4 & \\
\hline & & Agak Curam & 3 & \\
\hline & & Curam & 3 & \\
\hline & & Sangat Curam & 1 & \\
\hline \multirow{14}{*}{2} & \multirow{14}{*}{$\begin{array}{l}\text { Penggunaan } \\
\text { Lahan }\end{array}$} & Bandara & 4 & \multirow{14}{*}{0,073} \\
\hline & & Bangunan terpencar & 5 & \\
\hline & & Semak belukar & 2 & \\
\hline & & Pemakaman & 2 & \\
\hline & & Ladang & 3 & \\
\hline & & Tanah kosong & 1 & \\
\hline & & Pasir & 1 & \\
\hline & & Pemukiman & 5 & \\
\hline & & Pohon & 1 & \\
\hline & & Rawa & 1 & \\
\hline & & Sawah & 4 & \\
\hline & & Sungai & 1 & \\
\hline & & Tambak & 4 & \\
\hline & & Tanggul & 1 & \\
\hline \multirow{3}{*}{3} & \multirow{3}{*}{ Jenis Tanah } & Tidak peka & 5 & \\
\hline & & Peka & 2 & 0,119 \\
\hline & & Sangat peka & 1 & \\
\hline \multirow{5}{*}{4} & \multirow{5}{*}{$\begin{array}{l}\text { Curah Hujan } \\
\text { (mm/tahun) }\end{array}$} & SMB II: & \multirow{5}{*}{4} & \\
\hline & & $\begin{array}{l}\text { Kilmatologi } \\
\text { Palembang: } 2760,6\end{array}$ & & \\
\hline & & Sekojo: $\quad 2625,2$ & & 0,246 \\
\hline & & 2519,8 & & \\
\hline & & Kertapati: $\quad 2609,9$ & & \\
\hline
\end{tabular}




\section{Analisis Weighted Overlay}

Metode untuk menentukan klasifikasi kawasan untuk penerapan sistem RWH berdasarkan nilai skor dan bobot setiap parameter dengan menggunakan analisis weighted overlay. Analisis tersebut mengklasifikasikan jenis kawasan menjadi kawasan yang sangat potensial, kawasan potensial, kawasan potensial sedang, dan kawasan tidak potensial. Kawasan dibagi berdasarkan sub DAS yang ada di Kota Palembang. Hasil analisis menghasilkan peta seperti Gambar 8.
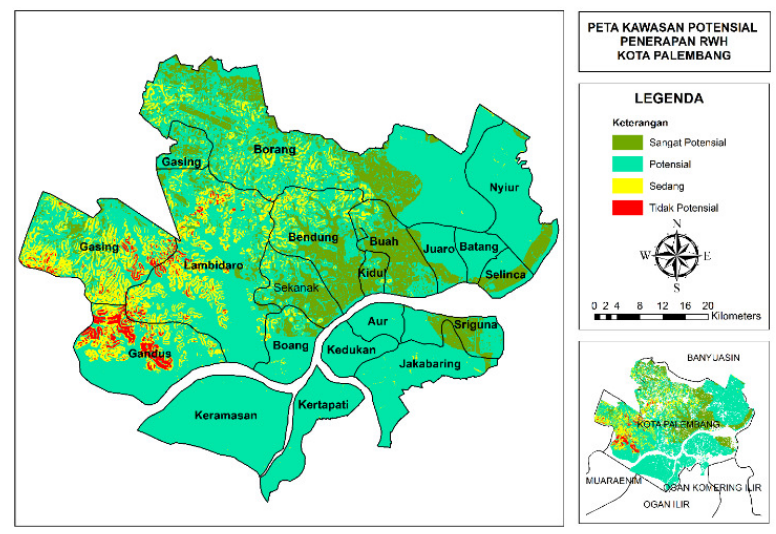

Gambar 8. Peta klasifikasi kawasan untuk penerapan sistem RWH

Berdasarkan analisis weighted overlay yang sudah dilakukan, kawasan padat permukiman dengan lereng datar dan jenis tanah yang tidak peka infiltrasi merupakan kawasan yang sangat potensial untuk penerapan sistem. Kawasan dengan kemiringan datar tetapi dengan jenis tanah sangat peka dan peka terhadap infiltrasi termasuk ke dalam klasifikasi kawasan yang potensial. Sedangkan kawasan yang tidak padat permukiman dengan lereng curam dan sangat curam merupakan kawasan tidak potensial,

Dari Gambar 8 dan Tabel 7, kawasan yang ada di Kota Palembang secara umum termasuk dalam klasifikasi kawasan potensial untuk penerapan sistem RWH. Luas kawasan yang sangat potensial dan kawasan potensial masing-masing mencapai $18,17 \%$ dan $66,14 \%$. Kawasan yang termasuk dalam kawasan potensial sedang dan kawasan tidak potensial berturut-turut sebesar $13,66 \%$ dan $2,03 \%$. Tabel 7 berikut menjelaskan persentase klasifikasi kawasan di Kota Palembang.
Tabel 7. Klasifikasi kawasan untuk penerapan sistem RWH di Kota Palembang

\begin{tabular}{|c|c|c|c|c|c|}
\hline \multirow[b]{2}{*}{ No. } & \multirow[b]{2}{*}{$\begin{array}{l}\text { Kawasan/ } \\
\text { Sub DAS }\end{array}$} & \multicolumn{4}{|c|}{ Klasifikasi kawasan } \\
\hline & & $\begin{array}{c}\text { Kawasan } \\
\text { sangat } \\
\text { potensial }\end{array}$ & $\begin{array}{l}\text { Kawasan } \\
\text { Potensial }\end{array}$ & $\begin{array}{c}\text { Kawasan } \\
\text { potensial } \\
\text { sedang }\end{array}$ & $\begin{array}{c}\text { Kawasan } \\
\text { tidak } \\
\text { potensial }\end{array}$ \\
\hline 1 & Aur & $0,21 \%$ & $99,67 \%$ & $0,12 \%$ & - \\
\hline 2 & Batang & $4 \%$ & $96 \%$ & $0 \%$ & - \\
\hline 3 & Bendung & $44 \%$ & $39 \%$ & $17 \%$ & $0,07 \%$ \\
\hline 4 & Boang & $13 \%$ & $79 \%$ & $8 \%$ & $0,02 \%$ \\
\hline 5 & Borang & $29 \%$ & $60 \%$ & $11 \%$ & $0,04 \%$ \\
\hline 6 & Buah & $72 \%$ & $22 \%$ & $5 \%$ & $0,05 \%$ \\
\hline 7 & Gandus & $0 \%$ & $65 \%$ & $22 \%$ & $13 \%$ \\
\hline 8 & Gasing & $11 \%$ & $51 \%$ & $34 \%$ & $4 \%$ \\
\hline 9 & Jakabaring & $10 \%$ & $89 \%$ & $1 \%$ & $0,01 \%$ \\
\hline 10 & Juaro & $25 \%$ & $75 \%$ & $0 \%$ & - \\
\hline 11 & Kedukan & $0 \%$ & $99,9 \%$ & $0,08 \%$ & - \\
\hline 12 & Keramasan & $0 \%$ & $99,91 \%$ & $0,09 \%$ & - \\
\hline 13 & Kertapati & $0 \%$ & $99,66 \%$ & $0,34 \%$ & - \\
\hline 14 & Kidul & $67 \%$ & $31 \%$ & $3 \%$ & - \\
\hline 15 & Lambidaro & $6 \%$ & $62 \%$ & $29 \%$ & $3 \%$ \\
\hline 16 & Nyiur & $10 \%$ & $89,7 \%$ & $0,32 \%$ & - \\
\hline 17 & Sekanak & $53 \%$ & $38 \%$ & $8 \%$ & $0,02 \%$ \\
\hline 18 & Selinca & $43 \%$ & $57 \%$ & $0,01 \%$ & - \\
\hline 19 & Sriguna & $51 \%$ & $49 \%$ & $0,07 \%$ & - \\
\hline & Total (Ha) & 5204,329 & 18948,439 & 3914,496 & 582,196 \\
\hline & rsentase $(\%)$ & 18,17 & 66,14 & 13,66 & 2,03 \\
\hline
\end{tabular}

Sebagian besar sub DAS yang berada di bagian tengah dan utara dari Kota Palembang termasuk ke dalam kawasan yang sangat potensial untuk penerapan sistem RWH. Sub DAS Buah, Kidul, Sekanak, Sriguna, Bendung, dan Selinca termasuk dalam kawasan sangat potensial yang memiliki persentase luasan lebih dari $40 \%$. Sebaliknya, sebagian kecil kawasan di sub DAS Gandus, sub DAS Gasing, dan sub DAS Lambidaro termasuk dalam kawasan yang tidak potensial dengan luas masing-masing $13 \%$, 4\%, dan $3 \%$.

\section{KESIMPULAN}

1. Berdasarkan curah hujan, Kota Palembang termasuk wilayah yang memiliki potensi yang baik untuk penerapan sistem RWH.

2. Sebagian besar kawasan di Kota Palembang termasuk ke dalam klasifikasi kawasan potensial untuk penerapan sistem RWH. Kawasan sangat potensial dan kawasan potensial untuk penerapan sistem RWH masing - masing mencapai persentase luasan $18,17 \%$ dan $66,14 \%$. Luas kawasan dengan potensial sedang dan kawasan tidak potensial sebesar $13,66 \%$ dan $2,03 \%$.

3. Sub DAS yang termasuk dalam kawasan yang sangat potensial dengan persentase luasan besar berturut-turut berada di sub DAS Buah, Kidul, Sekanak, Sriguna, Bendung, dan Selinca.

4. Sub DAS di Kota Palembang yang termasuk dalam kawasan yang tidak potensial dan memiliki persentase luas yang lebih dari 3\% 
Cantilever | Volume: 9 Nomor: 1 | April 2020 ISSN: 1907-4247 (Print) $\mid$ ISSN: 2477-4863 (Online) $\mid$ Website: http://cantilever.id

Imroatul C. Juliana, dkk. | Identifikasi Kawasan Potensial untuk Penerapan Sistem RWH di Kota Palembang dengan Pendekatan GIS

yaitu di sub DAS Gandus, Gasing, dan Lambidaro.

5. Dengan analisis weighted overlay dapat disimpulkan bahwa kawasan yang didominasi penggunaan lahan yang padat permukiman, lereng dengan kemiringan datar, dan memiliki jenis tanah yang tidak peka terhadap infiltrasi diklasifikasikan ke dalam kawasan yang sangat potensial untuk penerapan sistem RWH. Kawasan dengan lereng yang datar tetapi memiliki jenis tanah peka dan sangat peka terhadap infiltrasi termasuk dalam kawasan potensial. Sedangkan kawasan yang didominasi dengan lereng dengan kemiringan sangat curam dan curam dan tata guna lahan tidak padat pemukiman termasuk dalam kawasan yang sedang dan tidak potensial.

\section{REFERENSI}

Adham, A., Sayl, K. N., Abed, R., Abdeladhim, M. A., Wesseling, J. G., Riksen, M., Fleskens, L., Karim, U., \& Ritsema, C. J. (2018). A GIS-Based Approach for Identifying Potential Sites for Harvesting Rainwater in The Western Desert of Iraq. International Soil and Water Conservation Research, 6(4), 297-304.

Al Amin, M. B., Sarino, \& Sari, N. K. (2015). Visualisasi Potensi Genangan Banjir di Sungai Lambidaro Melalui Penelusuran Aliran Menggunakan HEC-RAS Studi Pendahuluan Pengendalian Banjir Berwawasan Lingkungan. Seminar Nasional Teknik Sipil I (SeNaTS I), Universitas Udayana, Denpasar, 25 April 2015.

Bappeda Litbang Kota Palembang, (2017). Standarisasi Harga Satuan Upah, Bahan Dan Gedung Kota Palembang. Palembang .

BPS Kota Palembang (2018), Kota Palembang dalam Angka 2018. Palembang: BPS Kota Palembang.

Darmawan, K., Hani'ah, \& Suprayogi A. (2017). Analisis Tingkat Kerawanan Banjir di Kabupaten Sampang Menggunakan Metode Overlay dengan Scoring Berbasis Sistem Informasi Geografis. Jurnal Geodesi Undip. 6(1), 31-40.

Farreny, R., Gabarrell, X., \& Rieradevall, J. (2011). Cost Efficiency of Rainwater Harvesting Strategies in Dense Mediterranean Neighbourhoods, Journal of Resources, Conservation and Recycling, 55(7), 686-694.

Mahmoud, S., Alazba, P., Adamowski, J., \& El-Gindy, A. (2015). GIS Methods for Sustainable Stormwater Harvesting and Storage Using Remote Sensing for Land
Cover Data - Location Assessment. Environ Monit Assess. 187(9):4822.

Nagaraj, N., Pradhani, U., Chengappa, P. G., \& Basavaraj, G. (2011). Cost Effectiveness of Rainwater Harvesting for Groundwater Recharge in Micro Watersheds of Kolar District India, Agricultural Economics Research Review, 24(2), 217-223.

Nketiaa, A. K., Forkuob, E. K., Asamoaha, E., \& Senayaa, J. K. (2013). Using A Gis-Based Model as A Decision Support Framework for Identifying Suitable Rain Water Harvesting Sites. International Journal of Advanced Technology \& Engineering Research (IJATER), 3(4), 25-33.

Juliana, I., C., Syahril, M., \& Cahyono, M. (2014). Analisa Potensi Curah Hujan untuk Penerapan Sistem Rainwater Harvesting di Kota Palembang, Prosiding Seminar Nasional Teknik Sipil X (pp. 667 - 676), ITS, Surabaya, 10 November 2014.

Juliana, I. C., Kusuma, M. S. B., Cahyono, M., Kardhana, H., \& Martokusumo, W. (2017). Performance Of Rainwater Harvesting System Based On Roof Catchment Area And Storage Tank Capacity, MATEC Web of Conferences 101 (05014), https://doi.org/10.1051/matecconf/201710105014.

Rahman, A., Keane, J., \& Imteaz M. A. (2012). Rainwater Harvesting in Greater Sydney: Water Savings, Reability and Economic Benefits, Journal of Resources, Conservation and Recycling, 61, $16-21$.

Roebuck, R. M. \& Ashley, R. M. (2006), Predicting The Hydraulic and Life Cycle Cost Performance of Rainwater Harvesting Sistem Using A Computer Based Modelling Tool, Proceeding 7th International Conference of Urban Drainage Modelling, Monash University, Melbourne, 2-7 April 2006.

Roebuck, R. M., Dumbrava, C. O., \& Tait, S. (2010). Whole life cost performance of domestic rainwater harvesting systems in the Unite Kingdom, Water and Environment Journal, 25 (3), 355-365.

Ryan, M. A., Spash, C. L., \& Measham, T. G. (2009). SocioEconomic and Psycological Predictors of Domestic Greywater and Rainwater Collection: Evidence from Australia, Journal of Hydrology, 379(1-2), 164-171.

Saaty, T. L. (1993). Pengambilan Keputuan Bagi para pemimpin, proses Hirarki Analitik untuk Pengambilan Keputusan dalam Situasi Kompleks. Seri Manajemen No. 134. Jakarta: PT. Pustaka Binaman Pressindo.

Tam, V. W. Y., Tam, L., \& Zeng, S.X. (2009). Cost Effectiveness and Tradeoff on the Use of Rainwater Tank : An empirical study in Australian residential decisionmaking, Journal of Resources, Conservation and Recycling, 54 (3), 178-186.

Zhang, Y., Chen, D., Chen, L., \& Ashbolt, S. (2009). Potential for Rainwater Use in High Rise Buildings in Australian Cities, Journal of Environmental Management, 91(1), 222226. 